\title{
Las gestiones de Fernández y el conflicto palestino-israelí: ajuste en un marco de continuidad de la política de equidistancia
}

\author{
Ornela Fabani*
}

\section{Resumen}

El objetivo del trabajo reside en describir y analizar el posicionamiento de las gestiones de Cristina Fernández (2007-2015) frente al conflicto palestino-israelí prestando particular atención a las instancias de cambio, ajuste y/o continuidad de la política de equidistancia que tradicionalmente Argentina ha abrazado frente a la disputa.

Con vistas a dicho análisis se parte de la siguiente afirmación: Durante las administraciones de Fernández, Argentina protagonizó un acercamiento a la contraparte palestina dando lugar a un ajuste de su política exterior frente al conflicto que se produjo en un marco general de continuidad de la política de equidistancia. Como correlato, en el periodo de referencia no existió un cambio en la política frente a la controversia que implique un quiebre del patrón de equidistancia, pero sí un ajuste de la misma.

Metodológicamente se opta por un abordaje cualitativo recurriendo tanto a la utilización de fuentes secundarias como primarias, entre ellas, entrevistas a informantes/actores clave.

\section{Palabras clave}

Política exterior; Argentina; conflicto palestino-israelí; equidistancia; ajuste.

\section{we}

\section{TITLE}

Fernández's administrations and the Israeli-Palestinian conflict: adjustment in a continuity framework of the equidistance policy

\section{Abstract}

The purpose of this paper is to describe and analyze the stance of Cristina Fernández's governments (2007-2015) in the Palestinian-Israeli conflict. Special attention is paid to patterns of change, adjustment and/or continuity in Argentina's policy of equidistance.

To this end, we work through the assumption that during Fernandez's administrations, while a general framework of continuity in Argentina's policy of equidistance before the conflict was still in place, Fernández's rapprochement with the Palestinian counterpart, suggests some sort of policy adjustment. Thus, we argue that throughout the stated period, there was no change in the Argentinean foreign policy towards the conflict that suggested a break in the policy of equidistance, but rather a pattern of adjustment.

The analysis relies on a qualitative methodology that looks at secondary and primary sources. Important insights are drawn from interviews with key actors.

\section{KEYWORDS}

Foreign policy; Argentina; Palestinian-Israeli conflict; equidistance; adjustment. 


\section{Introducción}

El conflicto palestino-israelí ha ocupado un lugar de relevancia dentro de la agenda de política internacional global por décadas. Ello en virtud de que, con el paso de tiempo, esta disputa ha dejado por saldo miles de muertes, el desplazamiento de familias completas, la problemática aún hoy vigente de los refugiados, destrucción de infraestructura física, amén de la imposibilidad de que ambos pueblos puedan desarrollarse en condiciones de paz y seguridad, sólo por mencionar algunas de las consecuencias que ha traído aparejadas esta contienda.

En lo que atañe a Argentina, históricamente dicho país ha adoptado una postura equidistante frente al conflicto, que se inaugura el 29 de noviembre de 1947 cuando Naciones Unidas decide llevar adelante una votación que marcaría el destino de los pueblos palestino e israelí. Desde entonces Buenos Aires ha defendido el derecho de Israel a vivir en paz con fronteras seguras e internacionalmente reconocidas, así como también el derecho del pueblo palestino a conformar un estado independiente, con territorio propio, ejerciendo su inalienable derecho a la autodeterminación. Aún más, cabe mencionar que el posicionamiento adoptado por el citado país frente a la contienda no ha mutado ni siquiera con el cambio de régimen político que sufrió Argentina tras el retorno a la democracia en 1981.

Ahora bien, dejando de lado el posicionamiento de las administraciones precedentes frente a la disputa, en este caso se busca indagar en la postura asumida frente a la misma por parte de los gobiernos de Cristina Fernández (2007-2015). De esta forma, el objetivo del trabajo reside en: describir y analizar el posicionamiento de las gestiones de Cristina Fernández frente al conflicto palestino-israelí prestando particular atención a las instancias de cambio, ajuste y/o continuidad de la política de equidistancia.

A los fines de dicho análisis se parte de la siguiente afirmación: Durante las administraciones de Cristina Fernández, Argentina protagonizó un acercamiento a la contraparte palestina dando lugar a un ajuste de su política exterior frente al conflicto palestino-israelí, que se produjo en un marco general de continuidad de la política de equidistancia. Como correlato, durante el periodo de referencia no existió un cambio en la política frente a la disputa, que implicase un quiebre efectivo del patrón de equidistancia, plasmándose en un alineamiento de Argentina para con alguno de los actores involucrados en la contienda, pero sí un ajuste de la misma.

En torno a la perspectiva metodológica escogida, se opta por un diseño cualitativo. Como correlato, el trabajo se apoya en fuentes primarias: comunicados de prensa de la Cancillería argentina; discursos de la presidenta; alocuciones de representantes argentinos ante diversos órganos de Naciones Unidas; declaraciones y comunicados de prensa de organizaciones comunitarias árabes, musulmanas y judías en los que se sienta posición frente al conflicto y, finalmente, entrevistas semiestructuradas. Estas últimas resultan un insumo de relevancia para el trabajo al incorporar la perspectiva de académicos, miembros de la Dirección de África del Norte y Medio Oriente de la Cancillería argentina (DANMO), representantes diplomáticos de estos países en Buenos Aires y miembros de organizaciones comunitarias locales. Mientras tanto, como fuentes secundarias se emplean: libros y publicaciones de diversos centros de investigación argentinos e internacionales y artículos de prensa argentina. 
Para cerrar este punto, el siguiente apartado se aboca a presentar una serie de conceptos e ideas relevantes para el estudio que se pretende realizar. Mientras tanto, en los posteriores se apunta a describir y analizar el posicionamiento argentino frente al conflicto, el cual se verá reflejado en la postura que el gobierno adoptó frente a las diversas crisis en terreno, asimismo, en el discurso y las acciones que generaron distintos miembros de esta gestión frente a diversos organismos y esquemas de cooperación regionales, internacionales y birregionales, como es el caso del MERCOSUR, las Naciones Unidas y las Cumbres América del Sur Países Árabes (ASPA).

\section{Ideas y conceptos necesarios para el análisis}

Teniendo en consideración lo hasta aquí expuesto se introducen una serie de conceptos e ideas que resultan centrales para este trabajo. En esta línea se concibe a la política exterior como una política pública ${ }^{1}$, que se expresa en un conjunto de decisiones y acciones tomadas por los gobernantes de un estado, en respuesta a ciertas demandas y determinantes internos tanto como externos, calculadas para cambiar o preservar las condiciones del contexto internacional siempre con el objetivo de promover los intereses y valores del estado en el sistema internacional².

Asimismo cabe agregar, esta política pública pretende dar visibilidad, plasmar la estrategia que se da la sociedad política, o parte de ella, para proponer modos de inserción del estado en el contexto mundial ${ }^{3}$. En tal sentido la inserción, o condición de ser tomada en cuenta por la política y la economía mundial ${ }^{4}$, ha sido una preocupación de primer orden de los gobiernos bajo estudio, que en gran medida han pretendido alcanzarla ampliando sus márgenes de acción autónoma. Entendiéndose por autonomía "la máxima capacidad de decisión propia que puede lograr un Estado teniendo en consideración los condicionamientos objetivos del mundo real"5. Esto nos lleva a pensar en la sinergia vigente entre estas dos nociones, centrales en todo análisis sobre política exterior argentina, que de hecho deben ser entendidas como complementarias y desde ningún punto de vista como excluyentes ${ }^{6}$, siendo funcionales la una a la otra.

Al respecto, es menester agregar que la estrategia de inserción que un estado diseñe, puede traer aparejadas repercusiones sobre el posicionamiento del país ante un conflicto de las características de la disputa entre palestinos e israelíes.

A modo de ejemplo, durante el gobierno del Presidente Menem (1989-1999) Argentina

\footnotetext{
1 INGRAM, Helen y FIEDERLEIN, Suzzane, "Traversing boundaries: a public policy approach to the analysis of foreign policy", The Western Political Quarterly, vol. 41, n4, 1988, p. 725.

2 PERINA, Rubén, "El estado de la política exterior y las relaciones internacionales", en PERINA, Rubén y RUSSELL, Roberto (Comp.), Argentina en el mundo (1973-1987), GEL, Buenos Aires, 1988, p. 13.

3 MIRANDA, Roberto, "El análisis de la política exterior argentina desde la perspectiva de las relaciones internacionales", Cuadernos de Política Exterior Argentina, Centro de Estudios en Relaciones Internacionales de Rosario, Ed. CERIR, Rosario, 1988, p. 22.

4 MIRANDA, Roberto, "El cambio externo y las estrategias internacionales de la Argentina", Relaciones Internacionales, Universidad Nacional de la Plata, La Plata, no 21, 2001, p. 169

5 PUIG, Juan Carlos (Comp.), América Latina: Políticas Exteriores Comparadas, GEL, Buenos Aires, 1984, p. 42

6 SIMONOFF, Alejandro, "Apuntes sobre las políticas exteriores argentinas. Los giros copernicanos y sus tendencias profundas", Instituto de Relaciones Internacionales, Universidad de La Plata, Serie Libros, no 3, 1999, p. 5
} 
buscó insertarse en el concierto internacional de la mano de la entonces principal potencia a nivel global, Estados Unidos, recortando espacios de acción autónoma e impulsando lo que ha sido catalogado como una inserción excluyente ${ }^{7}$. Fruto de su política acoplamiento ${ }^{8}$, durante la década de los noventa, el gobierno argentino protagonizó una serie de gestos favorables al gobierno de Israel en consonancia con la política asumida por Washington frente a la citada controversia. No obstante, la estrategia de inserción internacional del país cambió con la llegada al poder del Frente Para la Victoria (FPV) (2003-2015). Ello en virtud de que estos gobiernos percibieron la vigencia de un orden internacional "multipolar, plural, diverso y complejo" y reconocieron al país como un país en desarrollo, lo que favoreció que durante esta etapa Argentina dejase de concebir a Estados Unidos y a la Unión Europea como sus principales socios, que quedase atrás la búsqueda de reinserción en el "primer mundo", y que se optase por una diversificación de las relaciones externas, así como también por una política exterior de cariz autónomo.

En línea con el perfil ideológico de los gobiernos del FPV, más próximo a los países del Sur, y en coincidencia con la ya referida autopercepción del país en el escenario internacional, el diseño de política exterior del FPV incluyó entre sus ejes el fortalecimiento de las relaciones con los países en desarrollo, privilegiándose los vínculos con los estados de la región. En este marco, ya en su discurso de asunción, Fernández hizo referencia a América Latina como "nuestra casa" y al MERCOSUR como "nuestro espacio". De cualquier manera, la evolución del vínculo entre Argentina y los países árabes, así como el posicionamiento del país frente a la disputa palestino-israelí, también deben entenderse en virtud de la una política que apostó a la profundización del vínculo con otros Estados del Sur.

Respecto a la citada disputa, cabe mencionar que al hacerse referencia al conflicto se alude a aquella controversia que enfrenta al pueblo de Israel con el pueblo palestino, por el territorio de Palestina y que, asimismo, se inscribe dentro de una contienda aún mayor, el conflicto árabe-israelí que involucra al Estado de Israel y a diversos países árabes. En torno a la disputa que aquí interesa es importante señalar que el enfrentamiento entre palestinos e israelíes lleva ya décadas, si bien reviste plena actualidad en la agenda de política internacional global.

La cuestión palestina tuvo origen en 1947 cuando Naciones Unidas aprobó la resolución 181/11 de la Asamblea General que dispuso la partición del territorio de Palestina, estableciendo que un $56 \%$ del mismo pasase a manos judías, un $42 \%$ permaneciese bajo control árabe y que el $2 \%$ restante, que básicamente se reducía a Jerusalén, quedase bajo control internacional. En dicha oportunidad, Argentina fue uno de los diez países que se

\footnotetext{
7 MIRANDA, Roberto, "El cambio externo...", op. cit., p. 173.

8 RUSSELL, Roberto, TOKATLIAN, Juan G., "América Latina y su gran estrategia: entre la aquiescencia y la autonomía", Revista CIDOB d 'Afers Internacionals, n¹04, 2013, p. 162.

9 FERNÁNDEZ, Cristina, Discurso ante el Congreso Nacional del Radicalismo Popular, 16 de abril de 2015 http:// www.cfkargentina.com/cfk-en-el-congreso-del-radicalismo-popular/ [Consultado el 5 de febrero 2016]
} 
abstuvo en la votación. Al respecto, distintos especialistas (Rein ${ }^{10}$, Botta $^{11}$, Mendez ${ }^{12}$ ) se han volcado a estudiar los motivos que guiaron a Buenos Aires a asumir esa posición. De cualquier forma, más allá de cuáles hayan sido las motivaciones iniciales, tal posicionamiento dio pie a lo que, con el correr del tiempo, se convertiría en el patrón de equidistancia argentino que ha tenido preeminencia frente a la controversia.

En torno al concepto equidistancia, el mismo es empleado por diversos autores que analizan la política exterior argentina hacia Medio Oriente ${ }^{13}$. No obstante, en este caso se tendrá en consideración el aporte de Ménde $z^{14}$ quien define equidistancia como la preocupación de las distintas administraciones nacionales por compensar cualquier gesto o acción que pudiera ser interpretado como un desnivel en el trato igualitario hacia los protagonistas principales de la controversia en Medio Oriente. Se asocia entonces la equidistancia con la histórica apuesta de los gobiernos argentinos en pos de sostener una posición equilibrada en lo referente a la disputa entre palestinos e israelíes, que ha coincidido con la voluntad de las sucesivas gestiones en el poder de preservar sus buenas relaciones no sólo con los países de Medio Oriente sino con el conjunto de actores que tienen intereses en juego en el conflicto.

Ahora bien, en línea con el objetivo de investigación que guía este artículo surge como interrogante si a lo largo de las administraciones de Fernández han existido instancias de cambio, ajuste, o si ha primado la continuidad de la tradicional política de equidistancia argentina frente a la disputa. En tanto, el concepto cambio alude a un realineamiento de la política exterior ${ }^{15}$, al abandono o reemplazo de una o más de las orientaciones de dicha política, y a las variaciones en los contenidos y/o formas de efectuar esa política ${ }^{16}$. Este concepto se contrapone a aquel de continuidad que implica el mantenimiento sin interrupción en el tiempo de determinadas orientaciones y contenidos en una o varias áreas de cuestiones de la política exterior y en la dinámica básica del proceso de toma de decisiones. Mientras que los ajustes deben comprenderse como variaciones en la intensidad del esfuerzo y adecuaciones de objetivos frente a uno o varios temas de la agenda externa ${ }^{17}$.

10 REIN, Raanan, Argentina, Israel y los judíos, Ediciones Lumiere, Buenos Aires, 2007.

11 BOTTA, Paulo, "La diplomacia Argentina y la partición de Palestina desde el punto de vista de sus protagonistas", África del Norte y Medio Oriente, Córdoba, vol. I, nº I, 2010, pp. 5-27.

12 MENDEZ, Norberto, "El rol de las colectividades árabe/islámica y judía respecto del Medio Oriente (1947-2007). Peso, influencia y presiones de las colectividades en relación con la política interior y exterior del Estado argentino y sobre la sociedad civil argentina global en lo concerniente al conflicto de Medio Oriente y las relaciones interestatales entre la Argentina y países de esta área. La existencia o no de un lobby judío", Tesis Doctoral, Facultad de Ciencias Jurídicas y Sociales, Universidad Nacional de la Plata, 2008, p. 89.

13 Ver los siguientes trabajos: CARRANCIO, Magdalena, "La política exterior Argentina y Medio Oriente", en La Política Exterior del Gobierno de Menem. Seguimiento y reflexiones al promediar su mandato, Ed. CERIR, Rosario, 1994, pp. 279-309; KLICH, Ignacio, Argentina, the Middle East and the Jews, Universidad de Westminster, Westminster, 1997; BOTTA, Paulo, "La diplomacia Argentina...", op. cit.; VAGNI, Juan, "Argentina-Marruecos. De los impulsos a la convergencia político comercial (1989-2007)", Tesis Doctoral, Facultad de Ciencia Política y Relaciones Internacionales, Universidad Nacional de Rosario, 2008; y PAREDES, Rubén, Las relaciones Argentina-Medio Oriente. Un recorrido a lo largo de 1983-2011, Ponencia presentada en el XI Congreso Nacional y IV Congreso Internacional sobre Democracia, Universidad Nacional de Rosario, 8 al 11 de septiembre de 2014.

14 MÉNDEZ, Norberto, "El rol de las colectividades árabe/islámica...", op. cit., p. 89.

15 VAN KLAVEREN, Alberto, "Entendiendo las políticas exteriores latinoamericanas: Modelo para armar", Estudios Internacionales, Santiago de Chile, vol. 25, no 98, 1992

16 RUSSELL, Roberto, Variables Internas y Política Exterior, Ponencia presentada en el Taller de Trabajo sobre Cuestiones Técnicas y Metodológicas para el Estudio de la Política Exterior, FLACSO, Buenos Aires, 18 y 19 de abril de 1991 , p. 10.

17 HERMANN, Charles, "When governments choose to redirect foreign policy", International Studies Quarterly, 
Tras esta presentación de naturaleza conceptual se busca indagar en la evolución del vínculo con las partes en el conflicto.

\section{La primera aproximación a las partes en la disputa}

Si bien las relaciones con Medio Oriente tradicionalmente no han ocupado un lugar de privilegio dentro de la agenda externa argentina, los gobiernos de Fernández se caracterizaron por intentar fortalecer los lazos con este espacio a través de diversas acciones. Tal es así que la mandataria buscó el acercamiento con la región a partir de una activa participación en las cumbres ASPA, un espacio de encuentro birregional cuya conformación en 2005 ha supuesto un hito en la historia de las relaciones entre los países sudamericanos y los Estados árabes. Sin ir más lejos, a escasos días de iniciado el primer gobierno de Fernández, Argentina fue sede de un encuentro de cancilleres del ASPA que derivó en la firma de la Declaración de Buenos Aires. Por otra parte, en febrero de 2008, reabrió sus puertas la Oficina de la Liga Árabe en el país con vistas a impulsar los vínculos entre Argentina y los miembros de la organización, objetivo acorde con lo estipulado en la Declaración de Brasilia (2005). Sumado a ello, durante esta etapa proliferaron las visitas y encuentros de negocios a nivel bilateral tanto con los países árabes como con el Estado de Israel. Sin pretender exhaustividad, durante su primera gestión la presidente realizó una gira que la llevó a Egipto, Túnez, Argelia y Libia en 2008 y, asimismo, ese año recibió al rey de Jordania. Mientras que, en 2009, Buenos Aires recibió al ministro de Relaciones Exteriores de Emiratos Árabes, al presidente de la ANP, al canciller y, luego, al presidente de Israel. En 2010, al emir y al primer ministro de Qatar, al primer ministro de Kuwait y al Presidente sirio Bashar Al Assad. Además, en 2011 la presidenta se dirigió a Kuwait, Qatar y Turquía, y el canciller argentino a Israel. Cabe agregar que este periodo también fue propicio para que prosperaran las consultas políticas, las reuniones de comisión mixta y las misiones comerciales.

En lo que respecta a la génesis del acercamiento entre los gobiernos de Fernández y las partes en la disputa que aquí interesa, vale mencionar que a poco de iniciada su primera gestión, Argentina participó de la Conferencia de Donantes para Palestina de diciembre de 2007, un encuentro que tuvo por fin recaudar fondos para viabilizar la creación del Estado palestino. Al respecto, si bien en dicha instancia no existió un compromiso argentino de realizar un aporte económico con tal fin, Buenos Aires se manifestó dispuesto a colaborar en el esfuerzo conjunto por alcanzar la paz en Medio Oriente por medio de proyectos de trabajo que se canalizarían mediante el Fondo Argentino de Cooperación Horizontal (FO-AR) ${ }^{18}$. De hecho, el país ya contaba con experiencia en la aplicación de este esquema en Palestina pues se había trabajado en materia urbana en Gaza, Belén y Ramallah, en el área salud en la lucha contra la brucelosis, entre otros esfuerzos realizados en la zona durante el segundo gobierno del Presidente Menem.

Posteriormente, un acontecimiento de mayor trascendencia que tomó lugar a sólo meses del arribo al poder de la nueva administración fue la apertura de la Oficina de Representación Argentina en Ramallah a mediados de 2008. Al respecto, si bien el Presidente Kirchner (2003-

Tucson, vol. 34, n¹, 1990, p. 5.

${ }^{18}$ El Fondo Argentino de Cooperación Horizontal (FO-AR) permite brindar ayuda técnica a países de igual o menor grado de desarrollo relativo mediante el envío de expertos, la recepción de técnicos en organizaciones locales o la organización de seminarios en los países que así lo requieran. 
2007) había firmado el decreto que autorizaba la apertura de la oficina, ésta recién abrió sus puertas tres años después, bajo la gestión de su sucesora. De esta forma, Argentina pasó a tener representación en territorio palestino, pudiendo interpretarse la decisión de abrir esta oficina como una medida de apoyo a la construcción de un Estado palestino, que permite comenzar a pensar en una política exterior más activa frente al conflicto en relación a la gestión precedente e, incluso, en el nacimiento de una instancia de ajuste de la misma favorable a la contraparte árabe. Aún más, se estima que esta decisión política estuvo acorde con el perfil ideológico de este gobierno, más próximo a las realidades de los países en desarrollo pero que, asimismo, buscó convertirse en un vehículo para la profundización de los lazos tanto políticos como comerciales con el conjunto de los países árabes en una instancia en la que Argentina buscaba diversificar mercados.

Como contrapartida, el acercamiento entre el nuevo gobierno e Israel tampoco se hizo esperar. A la ceremonia de traspaso de mando presidencial asistió una delegación israelí encabezada por el Ministro del Interior, Meir Sheetrit, que días después se reunió con el entonces Canciller argentino, Jorge Taiana, para tratar algunos de los grandes temas de la agenda bilateral tales como la situación en Medio Oriente y el devenir del caso AMIA. A partir de entonces, y durante toda la primera gestión de Fernández, el vínculo con Israel fue fluido destacándose particularmente los avances en el ámbito económico-comercial. Tal es así que, mientras la administración Kirchner había logrado alcanzar en 2005 un superávit record con Tel Aviv ${ }^{19}$, la primera administración de Fernández alcanzó un nuevo record esta vez en términos del volumen de intercambio, que ascendió a los U\$\$ 411 millones en 2011, con un saldo favorable a Argentina que superó los U\$\$ 54 millones $^{20}$. Aún más, como corolario de la profundización de los lazos en materia comercial, en 2011 Argentina ratificó el Tratado de Libre comercio (TLC) MERCOSUR-Israel. Ahora bien, es importante mencionar que el intercambio comercial con Tel Aviv se resintió progresivamente a lo largo de la segunda gestión de la mandataria ${ }^{21}$, en línea con una retracción del comercio entre Israel y el conjunto de los país latinoamericanos que durante el segundo semestre de 2014 alcanzó un 14\%.

\section{El posicionamiento argentino frente a la disputa durante el primer gobierno de Fernández}

A los fines de analizar cómo se posiciona el país frente al conflicto, en el siguiente apartado se tendrá en consideración la postura adoptada por Argentina en distintos momentos de tensión entre las partes, así como también en el marco de la II Cumbre ASPA que tomó lugar en 2009.

Dicho esto, transcurrido poco más de un año de la asunción del gobierno de Fernández, el ejército israelí ingresó en la Franja de Gaza dando inicio a la Operación Plomo Fundido, una acción que despertó un fuerte debate y gran preocupación tanto en el ámbito internacional como local. Al punto que el gobierno argentino debió lidiar con las presiones de las comunidades árabe, islámica y judía en el país que buscaron imponer su propia visión frente a la disputa.

\footnotetext{
19 FUNDACIÓN EXPORTAR, "Análisis de oportunidades comerciales para el incremento de las exportaciones argentinas hacia Israel", Ministerio de Relaciones Internacionales, Comercio Exterior y Culto, Informe n 34 , 2008, p. 39

20 BOZZOTTI, Agustín y DI JULIO, Inés, "Informe para viaje de negocios", Fundación Exportar, Ministerio de Relaciones Internacionales, Comercio Exterior y Culto, 2016

21 Ibídem.
} 
Respecto a estos grupos, indicadores de distinto tipo muestran la importancia que los mismos guardan en el país. Tal es así que en la actualidad la comunidad árabe se erige como la tercera en relevancia en Argentina ${ }^{22}$, mientras que la comunidad judía es la más grande en Latinoamérica23. De allí el interés de los sucesivos gobiernos nacionales por procurar mantener un estrecho vínculo con las mismas y por evitar cualquier conflicto que pueda surgir con ellas ${ }^{24}$.

Lo cierto es que sostener este buen nivel de relaciones puede tornarse una tarea difícil en aquellos momentos en los cuales se profundizan los enfrentamientos entre las partes. Sin ir más lejos, como consecuencia del desencadenamiento de la Operación Plomo Fundido, distintas organizaciones de la colectividad árabe e islámica en Argentina se manifestaron en contra del accionar de Tel Aviv por medio de la emisión de comunicados de prensa y de la organización de marchas hacia la Embajada de Israel. Entonces, en una movilización que tomó lugar el 8 de enero de 2009, el titular de la Federación de Entidades Argentino Árabes (FEARAB) señaló:

"Los gobiernos tienen las herramientas necesarias para parar este genocidio, apelando a la suspensión de las relaciones diplomáticas, aplicando sanciones económicas y hasta promoviendo la suspensión de Israel en los foros internacionales. No vamos a dejar de denunciar a quienes están siendo cómplices por acción u omisión de esta masacre" ${ }^{\prime 25}$.

En un discurso que bien puede ser leído como un intento de influir sobre la posición adoptada por el gobierno nacional frente al caso ${ }^{26}$. Por su parte la comunidad judía respondió con un acto organizado en la Asociación Mutual Israelita Argentina (AMIA) "en solidaridad con el pueblo y el Estado de Israel, que está sometido al terrorismo del grupo Hamas", luego del

22 DALMAZZO, Gustavo y FRANCISCO, Héctor, "Los credos de los turcos", Todo es Historia, n 412, 2001, p. 21

${ }^{23}$ REIN, Raanan, Argentina, Israel..., op. cit., p. 20.

${ }^{24}$ Entre 1870 y 1929, Argentina recibió aproximadamente 6.000.000 de inmigrantes. Cabe destacar que, pese a que los principales flujos migratorios provinieron de Italia y España, durante el mismo período el país también recibió un gran número de inmigrantes árabes y judíos. Ver: ALONSO, María, ELISALDE, Roberto, VAZQUEZ, Carlos, Historia Argentina y el Mundo Contemporáneo, Aique Grupo Editor, Buenos Aires, 1994.

Respecto a estos últimos, un amplio porcentaje de la población judía que llegó a Argentina provino de Europa Oriental, en particular del Imperio Ruso, donde los judíos eran objeto de prácticas discriminatorias, así como también de violencia estatal. En lo que atañe a los inmigrantes árabes, Akmir señala que un 90\% provino de los actuales territorios de Siria y el Líbano. Ver: AKMIR, Abdeluahed, Los árabes en Argentina, Editora UNR, Rosario, 2011

${ }^{25}$ RED DE MEDIOS ALTERNATIVOS, "Marcha en repudio a la matanza en la Franja de Gaza", 9 de enero de 2009 : http://www.rnma.org.ar/nv/index.php?option=com_ content\&task=view\&id=510\&Itedim = [Consultado el 25 de mayo 2016]

${ }^{26}$ En Argentina existe un alto grado de centralización del proceso de toma de decisiones en materia de política exterior en torno al Poder Ejecutivo y, más específicamente, en relación a la figura presidencial. En cuanto al Ministerio de Relaciones Exteriores, su subordinación a la conducción política del Ejecutivo resulta incuestionable. De cualquier forma, si bien la adopción de la decisión se produce en el ámbito de lo que Russell denomina la "estructura", los actores no gubernamentales buscan participar del proceso intentando incidir sobre el mismo. Para mayor información sobre el proceso de formulación de la política exterior en Argentina, el rol de las distintas reparticiones gubernamentales y la incidencia de las organizaciones comunitarias locales ver: Fabani, Ornela, "Política exterior argentina frente al conflicto palestino- israelí. Condicionantes internos y externos que contribuyen al predominio del tradicional patrón de equidistancia frente al caso (1983-2011)", trabajo presentado para la obtención del Doctorado en Relaciones Internacionales, Facultad de Ciencia Política y Relaciones Internacionales de la Universidad Nacional de Rosario (UNR), 2015; y Fabani, Ornela, "Las organizaciones comunitarias locales y el proceso de formulación de la política exterior argentina ante la disputa palestino israelí a través de las voces de sus representantes", Revista de Iniciação Científica em Relações Internacionais, Universidades Federal do Paraíba, Vol. 2, No 4, 2015, pp. 56-79. 
cual dicha institución junto con la Delegación de Asociaciones Israelitas Argentinas (DAIA) y la Organización Sionista Argentina (OSA) emitieron un comunicado en el que abogaron por la existencia de dos Estados viviendo en paz, aunque advirtieron que Hamas entiende que la solución al conflicto pasa por la destrucción del Estado de Israel27.

En este marco, la postura del gobierno de Fernández quedó plasmada en los comunicados de prensa emitidos por el Ministerio de Relaciones Exteriores y en las intervenciones argentinas en los debates en diversos órganos de Naciones Unidas en donde, en línea con la tradicional política de equidistancia argentina, se condenó el recurso a la violencia por ambas partes.

En un primer comunicado, la administración Fernández dio a conocer su preocupación por el agravamiento de la situación en Medio Oriente y condenó la incursión israelí en Gaza, así como también el uso desproporcionado de la fuerza por parte de dicho país, reprobando asimismo el lanzamiento de misiles por parte de grupos palestinos contra territorio israelí28. En tanto, poco después se condenó el ataque a un Centro de Refugiados de Naciones Unidas y a un hospital palestino, recordando a Israel sus obligaciones de acuerdo con el derecho internacional humanitario, y reclamó a ambas partes un cese al fuego ${ }^{29}$.

Fuera del ámbito de la retórica y ya en el ámbito de la práctica, frente a la difícil situación que se vivía en terreno, este gobierno decidió brindar ayuda a la población palestina tras una solicitud de asistencia humanitaria cursada por el representante de la ANP en Argentina ante la Comisión de Cascos Blancos de la Cancillería, en otra acción que expone una aproximación de Argentina a Palestina. En efecto, Buenos Aires respondió a dicho pedido con el envío de una serie de insumos básicos que faltaban en la zona, complementando su colaboración con la formación de un equipo médico que viajó a la región, en una acción coordinada por Cascos Blancos.

Es más, una vez acatado el alto al fuego, Argentina fue uno de los cinco países latinoamericanos que participó de la Cumbre Internacional para la Reconstrucción de Gaza que tuvo lugar en Egipto en marzo de $2009^{30}$. Allí, en virtud de su experiencia previa fruto de las misiones desempeñadas por Cascos Blancos argentinos en la zona entre 1996 y 2000, se ofreció poner a disposición recursos técnicos y humanos para auxiliar a la población palestina.

En otro orden, y trazando un paralelismo con la gestión de Néstor Kirchner, es oportuno mencionar que en esta oportunidad la administración Fernández se mostró más diligente que la de su antecesor frente al sufrimiento de una de las partes en el conflicto: el pueblo palestino. Pues, si bien durante la gestión de Kirchner, Arafat y el entonces representante de la ANP en Argentina, Suhail Akel, solicitaron que Cascos Blancos argentinos brindasen ayuda humanitaria a la población palestina, no obtuvieron respuesta. En esta línea, la actitud del gobierno de Fernández bien puede comprenderse en función del rol que la problemática de

\footnotetext{
27 LA GACETA, "Acto de apoyo a Israel en la sede de la AMIA", 9 de enero de 2009.

28 MINISTERIO DE RELACIONES EXTERIORES Y CULTO DE LA REPÚBLICA ARGENTINA, Información para la Prensa n० 002/2009, 3 enero de 2009

29 MINISTERIO DE RELACIONES EXTERIORES Y CULTO DE LA REPÚBLICA ARGENTINA, Información para la Prensa n० 009/2009, 15 de enero de 2009

${ }^{30}$ Junto a Argentina participaron de este evento Brasil, Chile, México y Venezuela.
} 
derechos humanos asumió para dicha administración, convertida en uno de los principales ejes tanto de política interna como externa, pero también en virtud de la ya referida búsqueda de profundizar los vínculos tanto políticos como comerciales con los países de la zona.

Dicho esto, es menester mencionar que pese a la aproximación que Argentina comenzaba a transitar con la parte Palestina, Buenos Aires estuvo lejos de atender a las demandas de las comunidades árabe y musulmana locales en el sentido de que este país no se planteó la posibilidad de una ruptura de relaciones diplomáticas con Israel, en línea con el proceder de otros países vecinos como es el caso de Bolivia y Venezuela; una acción que, por otra parte, hubiese implicado no ya un ajuste sino un cambio de la política exterior argentina frente al conflicto.

Tiempo después, en marzo de 2009, tomó lugar la II Cumbre ASPA convirtiéndose este encuentro en el ámbito propicio para que Argentina volviese a posicionarse frente al conflicto palestino-israelí. De hecho, en el marco del evento la cuestión palestina resultó de abordaje obligatorio considerando que las consecuencias de la Operación Plomo Fundido se encontraban aún latentes. Entonces, Fernández señaló: "Malvinas y Palestina son ejemplos terribles de no cumplimiento de las normas de organismos internacionales sobre derechos de otros países"31, en un intento por relacionar dos causas caras a los intereses árabes y argentinos que evidencia la referida instancia de ajuste de la política exterior argentina frente al conflicto de la cual se intenta dar cuenta. Esta afirmación, por otra parte, no estuvo exenta de críticas y generó cierto malestar tanto en el vínculo con las instituciones de la comunidad judía local como con el Estado de Israel.

Respecto al por qué de la asociación de ambas causas, hay quienes señalan que la vinculación de estos dos conflictos puede entenderse en línea con un intento de la presidenta de sumar el apoyo árabe a la causa Malvinas. Lo cual, al menos en el marco de este evento se logró, dado que la declaración final de la cumbre incorporó el reclamo argentino en pos de retomar el diálogo por la soberanía de las Islas. De cualquier forma, en este caso seguramente también tuvo un rol relevante la búsqueda del gobierno argentino de impulsar los vínculos económicos y comerciales con los países árabes en un escenario atravesado por la crisis financiera internacional. Frente a dicha eventualidad, el gobierno argentino juzgaba que muchos países desarrollados se estaban volcando al proteccionismo, frente a lo cual se tornaba imperioso "diversificar destinos". En ese marco se defendía la idea de que frente a un cambio de época se precisaban nuevos socios políticos y comerciales, entre los cuales se destacaba el rol que adquirían los países del mundo árabe valorados por el entonces Ministro de Agricultura argentino, Norberto Yauhar, como: "Ios que van a tener mayor crecimiento en los próximos años, son los que tienen mayor estabilidad comercial y son los que tienen mucho más que ver con nosotros en estos momentos que, por ejemplo, la Comunidad Europea"32.

En otro orden de cuestiones, como producto del ataque de Israel a la flotilla humanitaria que en mayo de 2010 intentó acercar ayuda a Gaza, las instituciones árabes e islámicas

\footnotetext{
${ }^{31}$ LA NACIÓN, "Polémico reclamo por Malvinas en Qatar", 1 de abril de 2009.

32 TELAM, "Yahuar: estamos en un cambio de épocas, con nuevos socios políticos y comerciales", 25 de noviembre de 2012: http://www.telam.com.ar/nota/45060/ [Consultado el 12 de febrero de 2016].
} 
locales volvieron a alzar sus voces contra la política del dicho Estado. De esta forma, en un comunicado de prensa de la Organización Islámica Argentina (OIA), del 31 de mayo de 2009, consta:

\begin{abstract}
"Hacemos un recordatorio a los parlamentarios argentinos y al gobierno nacional, para que observen con atención estas acciones del Estado sionista de Israel, al que proponen como socio del MERCOSUR y con el que se ha firmado un acuerdo de cooperación tecnológica en enero de 2009 mientras se producía el genocidio de Gaza. Recuerden y vean con sus propios ojos que el Estado de Israel ejerce el terrorismo en todas sus formas y asesina civiles con total impunidad"33.
\end{abstract}

Por su parte, la AMIA manifestó el respaldo de la comunidad judía argentina al Estado de Israel por medio de un acto organizado en la Sociedad Hebraica Argentina, según se anunció, con el objetivo de aportar al esclarecimiento de los hechos. Particularmente considerando que, según argumentó Israel, a través del accionar de la flotilla se pretendía introducir armas en el territorio de la Franja. Respecto a este incidente, como se verá a continuación, el gobierno nacional condenó el accionar de Israel en el marco del Consejo de Derechos Humanos de Naciones Unidas.

\title{
4. El reconocimiento argentino del Estado palestino y sus repercusiones
}

Hacia finales de 2010 Argentina fue uno de los países que decidió avanzar en el reconocimiento del Estado palestino. La ola de reconocimientos que tuvo lugar en esa fecha en gran medida fue fruto de la estrategia impulsada por la ANP que consistió en reclamar el mismo en distintos foros internacionales $y$, asimismo, en propiciarlo a través de visitas y encuentros oficiales.

En Sudamérica, Brasil, una nación que bajo el gobierno de Lula Da Silva buscaba posicionarse internacionalmente en un rol de liderazgo, se convirtió en punta de lanza al transformarse en el primer país de la región en reconocer al Estado palestino. Días después fue el turno de Argentina que, en el más claro símbolo de un ajuste de la política de equidistancia frente al conflicto, avanzó en la misma dirección siendo precedida por el conjunto de los Estados sudamericanos. Vale mencionar que, en la región, Colombia resultó la única excepción dado que el gobierno de Santos ha sostenido que el surgimiento del Estado palestino debe ser producto de una negociación y que de nada sirve su reconocimiento si el mismo no podrá vivir en paz, asumiendo así una posición en línea con la política estadounidense.

Ahora, en cuanto a la postura adoptada por Argentina cabe subrayar que esta no responde únicamente a un acompañamiento a la política exterior brasileña, sino que se explica en virtud de un conjunto de factores internos y externos. En este sentido, es ineludible mencionar el accionar de la ANP que, apostando por la acción diplomática, hacía tiempo venía impulsando una campaña a nivel internacional por el reconocimiento del Estado palestino. De hecho, como parte de la misma, Buenos Aires recibió la visita del Presidente Abbas en 2009. Aún más, las gestiones en pos del reconocimiento del Estado palestino también provinieron de parte de los países árabes considerando que ya en una reunión de cancilleres del ASPA,

${ }^{33}$ AGENCIA JUDÍA DE NOTICIAS, "Flotilla: Fuerte apoyo de la comunidad judía argentina a Israel tras el incidente en Gaza", 30 de junio de 2008: www.prensajudia.com/shop/detallenot. asp?notid=20062 [Consultado el 20 de marzo de 2014] 
que tomó lugar en Argentina a principios de 2008, el secretario general de la Liga Árabe había solicitado el apoyo de los países sudamericanos a la causa palestina. En efecto, la situación en Palestina también fue un tema que estuvo presente en las reuniones que Fernández mantuvo con el presidente de Egipto en 2008 y con su par sirio cuando éste visitó el país a mediados de 2010, amén de resultar ineludible en la II Cumbre ASPA de 2009. Por otra parte, es importante subrayar que, como ya se adelantó, Argentina no adoptaba esta decisión en solitario, sino que la misma era acorde con la postura de prácticamente la totalidad de los países de la región, entre ellos sus socios del MERCOSUR. Más aún, en enero de 2011 unos 120 países reconocían al Estado palestino -entre ellos China, India, Brasil, Sudáfrica y Rusia, países que pugnaban por ocupar un espacio de privilegio en el plano internacional- lo que habla de la existencia de un contexto internacional que era favorable al reconocimiento del Estado palestino. Al punto que incluso algunos Estados europeos, elevaron por esos días el estatus de sus misiones diplomáticas palestinas aunque sin llegar al reconocimiento pleno ${ }^{34}$. Esto en un marco caracterizado por la presentación de un informe del Banco Mundial en el que se reconocía que la ANP estaba bien posicionada para establecer un Estado. Finalmente, a la hora de adoptar la decisión de reconocer a este Estado, Argentina seguramente también tuvo presentes los crecientes vínculos políticos y comerciales que venía gestando con los países árabes. En este sentido, no puede dejar de señalarse que, si bien el volumen de comercio entre Argentina y los mismos era aún bajo se encontraba en franco crecimiento, habiéndose duplicado entre 2003 y $2007^{35}$. Entretanto, en el plano político, los vínculos entre Buenos Aires y los países árabes se vieron fortalecidos a partir del intercambio de visitas de alto nivel así como también vía el desarrollo de las cumbres ASPA cuya conformación, se insiste, supuso un paso decisivo en favor de una aproximación entre ambas regiones ${ }^{36}$.

En otro orden, y en este caso a diferencia del resto de sus pares sudamericanos, el reconocimiento argentino guarda una particularidad, pues como contrapartida de sus vecinos que reconocieron al Estado palestino sobre la base de las fronteras de 1967 o, en su defecto, sin pronunciarse sobre el tema fronteras ${ }^{37}$, Argentina lo hizo "dentro de las fronteras existentes en 1967 y de acuerdo a lo que las partes determinen en el proceso de negociación". De esta forma, todo indica que el gobierno argentino buscó dejar la puerta abierta a los reclamos israelíes en torno a ciertas porciones de dichos territorios en un intento por propiciar cierto equilibrio en lo referente al vínculo con los protagonistas de la disputa.

Al mismo tiempo, también acorde con la constante búsqueda de no malograr la relación con ninguna de las partes, el comunicado de prensa emitido por la Cancillería argentina para notificar el reconocimiento dio cuenta de que tradicionalmente Argentina ha defendido el derecho del pueblo palestino a constituir un Estado independiente, así como también el derecho del Estado de Israel a vivir en paz junto a sus vecinos, dentro de fronteras seguras

\footnotetext{
${ }^{34}$ Entre ellos los gobiernos de España, Inglaterra, Francia y Portugal. Mientras tanto el número de países europeos que elevaron el estatus diplomático de sus respectivas delegaciones palestinas se incrementó a lo largo de 2011.

${ }^{35}$ www.ccae.com.ar, Cámara de Comercio Argentino Árabe [Consultado el 1 de febrero de 2016]

36 MOYA MENA, Sergio, "Relaciones con Medio Oriente: ¿nuevo eje de la política internacional latinoamericana?", en Revista Relaciones Internacionales, Escuela de Relaciones Internacionales, Universidad de Costa Rica, vol. I, $\mathrm{n}^{\circ}$ 80, 2011: http://www.revistas.una.ac.cr/index.php/ri/article/view/122 [Consultado el 10 de marzo de 2016]

37 Brasil, Ecuador, Paraguay, Venezuela, Surinam, Guyana y Bolivia reconocieron al Estado palestino dentro de las fronteras de 1967, mientras que Chile, Perú y Uruguay no se pronunciaron sobre el tema fronteras.
} 
e internacionalmente reconocidas. De esta manera, se buscó compensar el reconocimiento del Estado palestino con el apoyo al derecho de Israel a vivir en paz y gozar de seguridad en línea con el tradicional patrón de equidistancia argentino frente al conflicto.

De acuerdo con la actual Directora a cargo de DANMO, Ruth Goycochea ${ }^{38}$, la postura Argentina frente al conflicto puede definirse como justa, equilibrada y coherente. Coherente con las resoluciones de Naciones Unidas, equilibrada a la hora de condenar el recurso a la violencia por ambas partes, y justa porque se contempla el derecho internacional. Además, la funcionaria subraya que la posición de Argentina no ha variado nunca desde 1947, descartando la idea de un cambio en la misma. Aunque al profundizar en los matices de esta política exterior reconoce que "quizás el gran matiz ha sido el reconocimiento de Palestina" que justifica en función de condicionantes externos. Particularmente, la posición adoptada no sólo por los países de la región sino también por China, la Federación Rusa, actores de Asia, África y el mundo árabe. De esta forma, los dichos de la funcionaria, abonan a la idea de un ajuste en un marco general de continuidad de la política exterior argentina frente al conflicto durante la gestión de Fernández.

En torno a cómo recibieron distintos actores involucrados en el conflicto la decisión adoptada por el gobierno argentino, el entonces Embajador palestino en el país, Walid Muaqqat ${ }^{39}$, señaló que Argentina dio "un paso audaz" y agregó que Brasil y Argentina abrieron el camino para el reconocimiento del Estado palestino por parte de los países de América Latina. Sin embargo, consultado sobre este punto, el primer Representante y Embajador palestino en el país, Suhail Akel${ }^{40}$, adoptó una posición más crítica al destacar: "Los países latinoamericanos reconocen un Estado soberano e independiente, ahí debería haber un punto. Argentina reconoce a Palestina dentro de las fronteras del 67' conforme lo que las partes acuerden en la mesa de negociación" en una postura que el Akel cataloga como "excesivamente ambigua". Conforme con su opinión, "El reconocimiento tiene que ser pleno, no reconociendo la seguridad de Israel. Caso contrario se estaría reconociendo a un Estado invasor". En esta misma dirección, David Comedi ${ }^{41}$, miembro de la Red Judía Internacional Antisionista, subrayó que reconocer a Palestina y mantener el vínculo con el Estado de Israel sólo lleva a mantener el status quo. Aunque reconoció "Estos reconocimientos son buenos para la lucha palestina porque los hace sentir acompañados después de tanto tiempo de aislamiento y abandono por parte de la comunidad internacional".

Como correlato, la contraparte israelí no recibió de buen agrado la decisión argentina, por el contrario, Yigail Palmor, Vocero del Ministerio de Relaciones Exteriores, la calificó como "decepcionante" y "lamentable"42. Mientras que el Embajador israelí en Buenos Aires, Daniel Gazit, en un tono más conciliador, afirmaba que Argentina tenía muy buenas relaciones con

${ }^{38}$ GOYCOCHEA, Ruth, directora de la Dirección de África del Norte y Medio Oriente de la Cancillería Argentina, 14 de marzo de 2013. Entrevista realizada por la autora.

${ }^{39}$ Entrevista realizada por la autora al Embajador Walid Muaqqat, Exembajador de Palestina en Argentina, Buenos Aires, 30 de septiembre de 2013.

${ }^{40}$ AKEL, Suhail, Exembajador de Palestina en Argentina, Buenos Aires, 6 de noviembre de 2013. Entrevista realizada por la autora.

${ }^{41}$ COMEDI, David, miembro de la Red Judía Internacional Antisionista, vía skype desde Córdoba, 15 de abril de 2013. Entrevista realizada por la autora.

${ }^{42}$ LA NACIÓN, "Israel califica de lamentable el reconocimiento de Palestina", 6 de diciembre de 2010. 
todos los países y que, por ende, se entendía que buscaba la solución pacífica del conflicto.

Fuera del ámbito estrictamente gubernamental, las comunidades árabe y judía argentinas también se manifestaron al respecto. De esta forma, a través de un comunicado FEARAB sostuvo que la declaración argentina era un aporte a la búsqueda de paz y de justicia por parte del pueblo palestino. Mientras que la AMIA hizo expreso su malestar a través de las declaraciones de su presidente quien aseguró que la postura argentina no contribuía a la paz en Medio Oriente ${ }^{43}$.

\section{Argentina frente a las incursiones en Gaza durante el segundo gobierno de Fernández}

En lo que atañe a otros sucesos que marcaron la evolución del conflicto, esta vez en el marco de la segunda gestión de Fernández, Argentina debió posicionarse frente a un nuevo recrudecimiento de la situación en terreno que derivó en la Operación Pilar Defensivo.

A raíz de esta ofensiva israelí en Gaza, en noviembre de 2012, la presidenta argentina asumió una postura activa y solicitó a través de una carta al Consejo de Seguridad de Naciones Unidas convocar a una reunión urgente de dicho órgano que pusiese fin a la nueva ronda de violencia en la zona, en tanto juzgó que la misma sólo fortalecía a quienes deseaban impedir la creación de un Estado palestino que conviviese en paz con el Estado de Israel ${ }^{44}$. Mientras que, en otra misiva, esta vez dirigida a los jefes de Estado de la UNASUR, efectuó una convocatoria a requerir al Consejo que solicitase a las partes el inmediato fin de las hostilidades. Es más, como parte de la misma señaló que para lograr el fin del conflicto el primer paso debía ser la creación de un Estado palestino libre e independiente, que negociase la paz de igual a igual con el Estado de Israel. Para luego agregar "La histórica decisión de las Naciones Unidas del 29 de noviembre de 1947 dando lugar a la creación de dos estados sigue vigente y urge que finalmente sea cumplida"45. En definitiva, a través de estas comunicaciones Argentina defendió, tal como históricamente lo ha hecho, la solución de dos estados al conflicto. Asimismo, brindó respaldo al Estado de Palestina en un momento particular, considerando que la comunidad internacional aún se debatía respecto a su ingreso a Naciones Unidas, en una instancia en la cual la mayoría de los países europeos, así como también Estados Unidos, seguían sin reconocer a este actor. Iniciada la Operación Margen Protector en julio de 2014, una vez más, la Cancillería argentina se posicionó ante el incremento de la violencia en terreno a través de una serie de comunicados en los cuales señaló que la población civil se encontraba atrapada en medio de las acciones armadas de Hamas y el uso desproporcionado de la fuerza militar por parte de Israel. Para luego agregar que Argentina condenaba de manera enérgica que Israel hubiese decidido escalar la crisis lanzando una ofensiva terrestre, así como también el continuo e indiscriminado lanzamiento de cohetes desde Gaza hacia Israel ${ }^{46}$.

\footnotetext{
${ }^{43}$ LA NACIÓN, "Contrapuntos entre árabes y judíos por la decisión oficial", 7 de diciembre de 2010.

${ }^{44}$ MISIÓN PERMANENTE DE ARGETINA ANTE NACIONES UNIDAS, "La presidente pidió a la ONU que llame a Israel y a Palestina al cese inmediato de hostilidades", 19 de noviembre de 2012: http://enaun.mrecic.gov.ar/content/ la-presidenta-pidio-la-onu-que-llame-israel-y-palestina-al-cese-inmediato-de-hostilidades [Consultado el 19 de junio de 2016].

${ }^{45}$ Ibídem.

46 MINISTERIO DE RELACIONES EXTERIORES Y CULTO DE LA REPÚBLICA ARGENTINA, Información para la Prensa n' 191/2014, 20 de julio de 2014.
} 
Cabe agregar que la Presidenta Fernández también se expresó frente a estos hechos en el marco de una cumbre del MERCOSUR donde efectuó un llamado al cese al fuego. En esta línea Fernández manifestó: "Hacemos un Ilamado al derecho de existir por parte del Estado de Palestina y al derecho del Estado de Israel a vivir también en paz en sus fronteras, lo que tiene que ser redituado con total exactitud".

En lo que respecta al ámbito local, la postura asumida por el gobierno nacional fue juzgada como tibia por parte del Comité Argentino de Solidaridad con el Pueblo Palestino, que exigió un embargo militar a Israel y solicitó la cancelación del TLC entre el MERCOSUR y dicho país. Según reza una nota leída en un acto organizado por el Comité:

"No aceptamos de manera alguna que se invoque la 'teoría de los dos demonios', de tan triste recordación en nuestro país, para justificar la salvaje agresión militar de que es objeto el pueblo palestino. Debemos recordar para todo efecto, que nos encontramos ante un estado ocupante y un pueblo bajo ocupación y no existe simetría posible entre ambas condiciones" ${ }^{\prime 4}$.

Es más, como parte de dicha misiva también se reivindicó la postura asumida frente a esta nueva crisis por otros gobiernos de la región como es el caso de Perú, Chile y El Salvador que a raíz de la situación en Gaza decidieron retirar sus embajadores de Israel. Sin embargo, en el caso de Argentina, aún pese al acercamiento que se venía transitando con la contraparte palestina, el gobierno se abstuvo de implementar una acción de la naturaleza del retiro de un embajador que hubiese supuesto un fuerte golpe sobre el ya lastimado vínculo bilateral tras la rúbrica por parte de Buenos Aires del memorándum con Irán.

\section{La evolución del vínculo con el Estado de Israel durante el segundo gobierno de Fernández}

Pese al impacto inicial que supuso el reconocimiento argentino del Estado de Palestina lo cierto es que el vínculo bilateral entre Argentina e Israel se mantuvo en un buen nivel a lo largo la primera gestión de Fernández. Sin ir más lejos, en 2009 Argentina recibió la visita de altas autoridades israelíes, este es el caso del entonces Canciller, Avigdor Lieberman, que llegó al país como parte de una gira por la región, en lo que se convirtió en la antesala de la visita a Buenos Aires del Presidente israelí, Shimon Peres. Paralelamente, en materia comercial las exportaciones de Argentina hacia Tel Aviv adquirieron dinamismo concentrándose fundamentalmente en dos sectores: carne bovina (44\%) y vehículos de navegación aérea, marítima y fluvial (31\%).

Tras el reconocimiento argentino del Estado de Palestina, Buenos Aires desplegó un conjunto de acciones en pos de desterrar cualquier recelo que se hubiese suscitado con el gobierno de Israel. En este marco el Canciller Timerman viajó a Tel Aviv, en abril de 2011, en una visita que puede interpretarse como un guiño del gobierno argentino hacia el Estado de Israel con el fin de propiciar, una vez más, el equilibrio que ha caracterizado al país al momento de posicionarse frente al conflicto. Como parte de su estadía en Israel Timerman se reunió con su par Avigdor Lieberman, fruto de dicho encuentro se iniciaron

47 RESUMEN LATINOAMERICANO, "Contundente movilización e Buenos Aires contra los bombardeos israelíes sobre Gaza", 17 de julio de 2014: http://www.resumenlatinoamericano.org/2014/07/17/contundente-movilizacionen-buenos-aires-contra-los-bombardeos-israelies-sobre-gaza/ [Consultado el 14 de julio 2014] 
conversaciones para la firma de un acuerdo aeronáutico y se rubricaron dos acuerdos, uno sobre telecomunicaciones, información y seguridad en la red, y otro en materia de inversiones. Además, en dicha oportunidad se anunció la ratificación por parte del Congreso argentino del TLC MERCOSUR-Israel ${ }^{48}$, permitiendo la plena entrada en vigor del acuerdo, ya ratificado por los restantes socios del bloque. Cabe agregar que el canciller argentino también encabezó una misión comercial multisectorial que participó de una ronda de negocios con contrapartes locales y abrió un seminario sobre oportunidades de negocios, comercio e inversiones entre Argentina e Israel. Como correlato, pese a la fricción que inicialmente provocó la decisión argentina de reconocer al Estado palestino, los vínculos económicos e intereses en juego en lo que atañe a la relación bilateral entre Argentina e Israel permitieron superar el mal trago.

Ahora bien, no obstante, el cariz de la relación durante el primer gobierno de Fernández la misma se resintió durante el segundo mandato de la presidente. Esto, fundamentalmente a raíz de la firma del Memorándum de Entendimiento con Irán ${ }^{49}$, un actor que se erige como la principal amenaza a la seguridad del Estado de Israel. Conforme con diversos analistas la firma de dicho documento supuso el golpe más fuerte en la historia de las relaciones bilaterales entre Argentina e Israel. El Exembajador argentino en Tel Aviv, Atilio Molteni, destaca que a partir de la firma del Memorándum Argentina dio un vuelco en su política hacia el Estado de Israel que implicó desconocer la relación bilateral con dicho país, en tanto define el accionar argentino como "un salto al vacío"50. Aún más, incluso hay quienes mencionan que las relaciones entre los referidos actores llegaron a romperse, aunque esto no se hubiese oficializado ${ }^{51}$.

También en esta dirección el vicecanciller de Israel señaló que firmar el acuerdo "equivale a invitar a un asesino a investigar sus crímenes"52. En aquel entonces la Cancillería israelí convocó al embajador argentino en Israel con el objetivo de que el mismo explicase los avances del acuerdo firmado con la República Islámica, en lo que Buenos Aires juzgó como "un acto impropio" en tanto se subrayó que ningún israelí había muerto en el atentado a la AMIA $^{53}$.

Es preciso aclarar que no sólo el Estado de Israel recibió negativamente la firma del acuerdo sino también gran parte de la comunidad judía local, provocando un deterioro del vínculo entre la misma y los gobiernos del FPV que no tenía antecedentes. Al respecto, las principales instituciones de la colectividad en el país, léase la AMIA y la DAIA, dieron su

${ }^{48}$ El tratado MERCOSUR - Israel fue firmado el 18 de diciembre de 2007. Argentina fue el último miembro del MERCOSUR en ratificarlo el 17 de marzo de 2011.

49 Tras el atentado que sufrió la sede de la AMIA, en 1994, se inició una investigación. En 2006 la justicia argentina concluyó que el gobierno de Irán se encontraba detrás del hecho. En este marco, tras una negativa sistemática a cooperar en la investigación cursada contra ciudadanos iraníes, en 2012, la República Islámica propuso a Buenos Aires iniciar un dialogo que derivó en la firma del Memorándum de Entendimiento. El punto más importante de dicho documento preveía la conformación de una Comisión de la Verdad que buscaría realizar avances en la investigación del atentado.

50 MOLTENI, Atilio, Exembajador argentino en Israel entre 2003 y 2010, Buenos Aires, 12 de marzo de 2013. Entrevista realizada por la autora

${ }^{51}$ Fuente anónima perteneciente a la Embajada de Israel, Buenos Aires, 13 de marzo de 2013. Entrevista realizada por la autora

52 LA NACIÓN, "Dura respuesta de Argentina a Israel por el caso AMIA", 30 de enero de 2013.

${ }^{53}$ Ibídem. 
espalda al Memorándum planteando incluso la inconstitucionalidad del mismo. Si bien es cierto que, un sector minoritario de la misma, dentro del cual se encuentra la agrupación Memoria Activa, mostró su beneplácito con la decisión del gobierno nacional de propiciar un acercamiento con Teherán con vista a poder avanzar en la investigación del atentado.

Cabe agregar que, aunque Argentina ensayó un acercamiento a Israel que se plasmó en otra visita del Canciller Timerman a Tel Aviv en 2014, una nueva desavenencia en las relaciones bilaterales sobrevino tras el discurso de Fernández de apertura de las sesiones ordinarias del Congreso en 2015. En aquella oportunidad la presidenta manifestó que Tel Aviv reclamaba por el esclarecimiento del atentado a la AMIA y no por la Embajada de Israel "que es territorio propiamente israelí", insinuando el desinterés de dicho país en la resolución del caso. En tanto, días después en respuesta a los dichos de Fernández, el Primer Ministro de Israel, Benjamín Netanyahu, denunció en un discurso frente al Congreso Republicano en Estados Unidos que Irán voló la Embajada de Israel en Buenos Aires e hizo mención a un centro comunitario en referencia a la AMIA.

Para cerrar este punto, lo cierto es que el segundo gobierno de Fernández arroja por saldo un deterioro del vínculo con Israel que Argentina se ha abocado a revertir a partir de la llegada al poder del gobierno de Mauricio Macri. Ahora bien, debe quedar claro que el referido malestar en la relación bilateral no respondió directamente al ajuste de la política exterior argentina frente al conflicto palestino-israelí sino, particularmente, a la postura que Buenos Aires adoptó frente a la causa AMIA, y a la evolución del vínculo entre Argentina e Irán.

\section{Argentina frente a la cuestión Palestina en Naciones Unidas (2007-2015)}

En lo que atañe al posicionamiento argentino frente al conflicto bajo análisis en el máximo organismo internacional, Naciones Unidas, en su presentación ante la $64^{\circ}$ Asamblea General Fernández subrayó la importancia de encontrar una solución al mismo por ser éste "un tema crucial en la seguridad y la paz internacional" destacando la importancia de que el pueblo palestino viva en su territorio y de que los ciudadanos de Israel también puedan hacerlo dentro de sus fronteras ${ }^{54}$.

En tanto, en el marco de un debate abierto del Consejo de Seguridad sobre la situación en Medio Oriente del 22 de julio de 2008, Buenos Aires manifestó su decepción como fruto de: la política de restricción al movimiento de los palestinos en Cisjordania, la continuación de la construcción del muro de separación dentro de la Línea Verde, la expansión de asentamientos israelíes en los territorios ocupados, los cierres de los pasos fronterizos en Gaza, y los continuos atentados terroristas gestados por parte de grupos radicales en Jerusalén. Mientras que, a principios de 2009, una vez iniciada la Operación Plomo Fundido, la delegación argentina condenó el accionar de Israel tanto como los ataques con cohetes de grupos palestinos. Luego, en una reunión del Consejo de Seguridad del 7 de enero, ante el incremento del número de víctimas palestinas, repudió los ataques israelíes y calificó su respuesta frente al accionar de Hamas como excesiva y desproporcionada. En esta misma dirección, abogó por un cese de las hostilidades permanente e incondicional y agregó que las tropas israelíes debían retirarse de Gaza y los ataques contra territorio israelí debían cesar.

${ }^{54}$ FERNÁNDEZ, Cristina, Discurso ante la 64 Asamblea General de Naciones Unidas, 23 de septiembre de 2009 
Por otra parte, ya en julio de 2014, ante el desencadenamiento de la Operación Margen Protector Argentina, en su carácter de miembro no permanente del Consejo de Seguridad, repudió el uso desproporcionado de la fuerza por parte del Estado de Israel. En consonancia, meses después, en una reunión de urgencia del Consejo de Seguridad del 29 de octubre, la delegación argentina condenó los anuncios de Israel respecto a una expansión de los asentamientos judíos en Jerusalén Oriental y, en un duro rechazo de los mismos señaló "Estos anuncios no sorprenden [...] Forman parte de la ininterrumpida campaña de colonización en Jerusalén Oriental, acompañada de confiscaciones, ataques contra civiles, demoliciones y desplazamientos forzosos de residentes palestinos". A la par que culpó a Israel de intentar modificar el status quo de los lugares sagrados de Jerusalén ${ }^{55}$.

Como miembro del Consejo de Derechos Humanos de Naciones Unidas la gestión Fernández, en línea de continuidad con el gobierno de Néstor Kirchner, una vez más votó "a favor" de la condena a Israel por la violación de los derechos humanos palestinos en los territorios ocupados. De esta forma, se evidencia que durante las administraciones del Frente Para la Victoria, Argentina ganó cierto margen de autonomía frente a Estados Unidos que en este caso se plasmó en un patrón de voto que no coincidió con aquél que adoptó el gobierno estadounidense, tal como supo ocurrir durante las presidencias de Menem.

Conforme con la política de defensa de los derechos humanos que abrazaron los gobiernos del Frente Para la Victoria, entre junio de 2008 y junio de 2011 Argentina votó en el citado órgano a favor de todas aquellas resoluciones que condenaban las violaciones de los derechos humanos en el territorio palestino ocupado, entre éstas: la confiscación de tierras y propiedades, la demolición de casas y propiedades privadas, la construcción y ampliación de asentamientos, la continuación de la construcción del muro de separación, la alteración de la configuración demográfica y geográfica de Jerusalén Oriental, las restricciones a la libertad de circulación de los ciudadanos palestinos de Jerusalén Oriental, la continuación de las obras de excavación en la mezquita Al-Aqsa y sus inmediaciones y, asimismo, de aquélla que reconoce el derecho del pueblo palestino a la libre determinación ${ }^{56}$.

En esta línea de análisis también debe mencionarse la posición que adoptó el país ante el ataque israelí, de mayo de 2009, a la flotilla que trasportaban ayuda humanitaria hacia la Franja de Gaza. Frente al mismo, en la $14^{\circ}$ reunión ordinaria del Consejo de Derechos Humanos el representante argentino sostuvo que Israel debía detener los ataques contra la población civil, haciendo especial referencia a los acontecimientos en la escuela de la Agencia de Naciones Unidas para los Refugiados de Palestina y a los ataques contra el transporte de ayuda humanitaria y, finalmente, votó a favor de la resolución A/HRC/14/1 que condena el ataque a la flotilla y sus consecuencias en cuanto a pérdida de vidas humanas ${ }^{57}$.

Ya en el marco del segundo gobierno de Fernández, Argentina junto a sus pares de la región (Chile, Brasil, Perú, Cuba y Venezuela), fueron algunos de los 29 países que votaron

\footnotetext{
55 MISIÓN PERMANENTE DE ARGETINA ANTE NACIONES UNIDAS, "La situación en el Oriente Medio incluida la cuestión Palestina", 29 de octubre 29 de 2012.

${ }^{56}$ Estas resoluciones son las siguientes: A/HRC/9/18, A/HRC/S-9/L.1, A/HR C/10/18, A/HRC/10/19, A/HRC/10/20, A/HRC/S-12/1, A/HRC/13/6, A/HRC/13/7, A/HRC/13/8, A/HRC/13/9.

57 PERFIL, "Argentina apoyó la investigación de la ONU al ataque israelí", 3 de junio de 2010.
} 
en el Consejo de Derechos Humanos a favor de una resolución, del 13 de julio de 2014, que prevé una investigación respecto a los hechos acaecidos en Gaza desde el inicio de la Operación Margen Protector.

En definitiva, vale destacar que durante los gobiernos de Fernández Buenos Aires fue constante en su reclamo contra las acciones de Tel Aviv que atentaban contra los derechos humanos de la población palestina y, a su vez, en su rechazo de aquellas perpetuadas por grupos radicales palestinos que tenían consecuencias sobre sus pares israelíes. Amén de ello, Argentina continuó con su histórica prédica en pos de una solución pacífica del conflicto fundada en la existencia de dos Estados. Por ende, existió correspondencia entre la retórica de estos gobiernos, vinculada tanto al respeto de los derechos humanos como a la promoción de la paz, y el posicionamiento asumido por el Estado argentino frente a la disputa. No obstante, pese a la búsqueda de mantener el equilibrio entre las partes, el perfil del voto argentino en el Consejo de Derechos Humanos, donde Argentina votó a favor de aquellas resoluciones relativas al conflicto que condenaban las violaciones de los derechos humanos en el territorio palestino ocupado, y efectuó constantes críticas al accionar de Israel, evidencian la referida instancia de ajuste de la política exterior argentina de la cual se intenta dar cuenta.

Finalmente, ante la solicitud de admisión de Palestina a Naciones Unidas en 2011, Fernández apoyó el ingreso de Palestina a la organización, en otra decisión que no sólo evidencia que dicho país logró obtener ciertos márgenes de autonomía frente a Washington, sino que también expone la referida instancia de ajuste de la política exterior argentina frente al conflicto de la que se busca dar cuenta. Al respecto, la primera mandataria sostuvo que, si bien para algunos impedir el ingreso de Palestina al organismo internacional podría ser visto como beneficioso para el Estado de Israel, abrazar esta postura implicaría seguir brindándoles coartadas a los que ejercen el terrorismo internacional y que encuentran en dicho desconocimiento una de las argumentaciones para intentar justificar sus crímenes. En consonancia, la presidenta agregó que la no inclusión de Palestina sólo reportaría mayor inseguridad y, por ende, abogó por que este Estado pudiese acceder al asiento número 194 en la organización ${ }^{58}$. De esta forma, Argentina complementó el reconocimiento bilateral del Estado palestino en diciembre de 2010, con el apoyo en el ámbito multilateral a su incorporación a Naciones Unidas dando, una vez más, respaldo a un Estado palestino que pueda vivir en paz junto al Estado de Israel en conformidad con el tradicional patrón de equidistancia argentino frente al conflicto ${ }^{59}$.

Al respecto, Arie Kacowicz ${ }^{60}$ señala que con los gobiernos del FPV Argentina "se ve como parte de América Latina, del tercer mundo [...] entonces en forma probablemente automática va a haber una identificación ideológica quizás mayor con la parte palestina". De cualquier forma, para comprender cabalmente la posición adoptada por dicho país es

\footnotetext{
${ }^{58}$ FERNÁNDEZ, Cristina, Discurso ante la 66 Asamblea General de Naciones Unidas, 22 de septiembre 2011.

59 TN, "Argentina reconoce a palestina como Estado Libre e independiente", http://tn.com.ar/politica/argentinareconoce-a-palestina-como-un-estado-libre-e-independiente_046773 [Consultado el 10 de febrero 2017] y MINISTERIO DE RELACIONES EXTERIORES Y CULTO DE LA REPÚBLICA ARGENTINA, Información para la Prensa n० 559/10, 6 de diciembre de 2010.

${ }^{60}$ Entrevista realizada por la autora a Arie Kacowicz, docente de la Universidad Hebrea de Jerusalén, efectuada vía skype en conexión con Israel, 06 de marzo de 2013.
} 
menester considerar que existieron múltiples factores que impulsaron la postura adoptada por Argentina.

En los últimos años la ANP había realizado importantes progresos en términos institucionales, a raíz de ello, informes de Naciones Unidas, el Fondo Monetario Internacional y el Banco Mundial daban fe de que las funciones de dicha entidad eran suficientes para ser consideradas las de un gobierno estatal. En dicho contexto, la Autoridad Palestina emprendió una activa campaña diplomática, que inmediatamente avalaron sus socios árabes, con el objetivo de concitar el apoyo de la comunidad internacional en pos del ingreso de Palestina como estado miembro de Naciones Unidas. En el plano local dicha campaña fue apoyada por las comunidades árabe e islámica por medio de la recolección de firmas en distintos puntos del país y a través de una marcha de estas organizaron hacia la sede de Naciones Unidas en Buenos Aires. Mientras tanto, el Grupo Parlamentario de Amistad con Palestina lo hizo por medio de la presentación de una nota en la cancillería solicitando el apoyo a Palestina en Naciones Unidas y a través de una invitación que se cursó al embajador de Palestina en el país, quien fue recibido en el Congreso Nacional donde pudo expresarse en torno a este tema. El accionar de la ANP, que como se señaló se inclinó por la vía diplomática y el recurso a los organismos internacionales, en esta oportunidad dio sus frutos ya que en el mes de octubre de 2011 la UNESCO aceptó el ingreso de Palestina como estado miembro. Ahora bien, si al accionar de estos actores se suman los crecientes vínculos políticos y comerciales que Argentina detentaba y apostaba a profundizar con los países árabes e, incluso, las transformaciones del sistema internacional asociadas a su carácter crecientemente multipolar, se tendrá un panorama más completo respecto al por qué de la posición que asume Buenos Aires.

En otro orden, se coincide con Kacowicz ${ }^{61}$ cuando éste sostiene:

"yo creo que desde el punto de vista de la política exterior argentina el reconocimiento al Estado palestino no lo ven como una postura anti israelí [...] o sea no es necesariamente una postura de suma cero, es una postura que de alguna forma complementa esa postura equidistante, porque lo que Argentina dice es [...] que el hecho de que ellos reconozcan al Estado palestino no es a costas del Estado de Israel sino al lado de Israel".

Precisamente por ello se hace referencia a un ajuste de la política exterior argentina, que se da un marco general de continuidad de la política de equidistancia, y no a un cambio de la misma.

Por otro lado, en lo que atañe al impacto de la postura asumida por Argentina sobre el vínculo con Israel una fuente perteneciente a la Embajada de Israel en el país expresa62: "Para Israel Argentina fue uno más, hubo sólo una excepción que fue Colombia todo el resto votó y Israel no por eso vio deteriorada su relación ni con Chile, ni con Brasil, que fueron otros países que votaron la misma resolución". También adhiere a esta postura el Exembajador argentino en Israel, Atilio Molteni63, quien destaca que este hecho tuvo un efecto limitado sobre el

\footnotetext{
${ }^{61}$ Ibídem.

62 Fuente anónima perteneciente a la Embajada de Israel, op. cit. Entrevista realizada por la autora.

${ }^{63}$ MOLTENI, Atilio, Exembajador de Argentina en Israel, vía skype en conexión con Buenos Aires, 3 de agosto de
} 
vínculo bilateral, particularmente atendiendo a la cantidad de países que reconocieron al Estado palestino. De esta forma, la recolección de datos efectuada respalda la idea de que el deterioro del vínculo con Israel durante la segunda gestión de Fernández no tuvo correlación directa con la decisión argentina de reconocer, tanto en el plano bilateral como multilateral, al Estado de Palestina. Por el contrario, para entender el porqué del alejamiento entre ambos actores es necesario atender a otros factores, previamente referidos, tales como el devenir de la causa AMIA y la evolución del vínculo entre Argentina e Irán.

Con referencia a la valoración que la contraparte árabe realiza respecto a la gestión Fernández se ha podido constatar que ésta es ampliamente positiva. Néstor Suleiman ${ }^{64}$, dirigente de la FEARAB, destaca que éste ha sido el gobierno más comprometido con la causa Palestina desde el retorno a la democracia, pues señala que más allá de las declaraciones efectuadas por otros gobiernos precedentes, este llevó adelante acciones concretas. Mientras tanto el Exembajador palestino en el país ${ }^{65}$, Walid Muaqqat, refiere que a través del tiempo el vínculo con Palestina "ha evolucionado de manera muy positiva fortaleciendo más las relaciones y acercándolas", lo que de acuerdo con el alto funcionario se plasmó en el reconocimiento del Estado palestino, el Acuerdo Palestina-MERCOSUR y el reconocimiento como estado en Naciones Unidas. Como corolario Muaqqat agrega: "Yo creo que Argentina ha cumplido todas las demandas palestinas". Esto lo lleva a concluir que las relaciones entre ambos países alcanzaron durante el gobierno de Fernández su punto máximo. De esta forma, al subrayar el acercamiento con Palestina y la solidez del vínculo que las partes supieron construir, estos informantes aportan a la idea de un ajuste de la política exterior argentina frente al conflicto sobre la cual se asienta el supuesto de partida de este trabajo. De hecho, como correlato de la evolución de la relación entre los dos países, previo a culminar su mandato, la presidenta recibió una condecoración del Estado palestino66.

Ahora bien, al no evolucionar la solicitud de admisión de Palestina como estado miembro de Naciones Unidas, Argentina fue uno de los países que copatrocinó el proyecto de resolución L.28 que apostó a lograr su ingreso como "estado observador no-miembro". Mientras que, el 29 de noviembre de 2012, Buenos Aires apoyó la resolución de 67/19 de la Asamblea General que, efectivamente, otorgó a Palestina el status de estado observador no miembro de la organización. En una alocución de la representante argentina ante la Asamblea General, la Embajadora Perceval, señaló que la resolución constituye sólo un paso hacia la decisión que la organización aún debe tomar que es la admisión de Palestina como estado miembro de las Naciones Unidas. A lo que agregó que si la Asamblea General aún no ha podido aceptar a Palestina en la organización esto es fruto de consideraciones ajenas a los requisitos establecidos en la Carta de Naciones Unidas que han hecho que el Consejo de Seguridad no hiciera recomendación alguna a la Asamblea, en una velada crítica a la postura adoptada frente a este tema por Estados Unidos. En esta línea recordó que Argentina, desde los inicios

2016. Entrevista realizada por la autora.

${ }^{64}$ SULEIMAN, Néstor, Secretario General de FEARAB, Rosario, 7 de julio de 2016. Entrevista realizada por la autora.

65 MUAQQAT, Walid, Embajador, op. Cit. Entrevista realizada por la autora.

66 INFOBAE, "Cristina Kirchner será condecorada por su apoyo a Estado al reconocimiento de Palestina como Estado", 8 de agosto de 2015: http://www.infobae.com/2015/08/08/1747071-cristina-kirchner-sera-condecorada-suapoyo-al-reconocimiento-palestina-como-estado/ [Consultado el 5 de abril 2016] 
de la organización, defendió la idea de que el derecho de veto de los miembros permanentes del Consejo no pudiera ejercerse respecto de la admisión de nuevos miembros. Asimismo, como parte de esta presentación, la representante argentina también defendió el derecho de Israel de vivir en paz y se manifestó a favor de una resolución definitiva del conflicto que enfrenta a dicho Estado con su par palestino ${ }^{67}$.

\section{Conclusiones}

Como balance del posicionamiento de las administraciones de Fernández frente al conflicto palestino-israelí, puede concluirse diciendo que el relevamiento de datos y el trabajo de campo efectuados demuestran que, durante sus gobiernos, Argentina protagonizó un acercamiento a Palestina que permite dar cuenta de la vigencia de una instancia de ajuste de su política exterior frente a la disputa. Este ajuste, coincidente con una variación en la intensidad del esfuerzo en torno al tema en cuestión, se constata, en primera instancia, al recordar que Argentina fue uno de los pocos estados latinoamericanos que participó de la Conferencia de Donantes para Palestina de finales de 2007. Asimismo, al considerar que el gobierno de Fernández abrió la Oficina de Representación Diplomática Argentina en Ramallah. Por otra parte, al tener en cuenta que, en 2009, Buenos Aires haciéndose eco del sufrimiento de la población palestina tras el desarrollo de la Operación Plomo Fundido decidió el envió de Cascos Blancos a la Franja Gaza. De cualquier forma, el hito durante este período, que no deja lugar a dudas respecto al referido ajuste de la política exterior del gobierno de Fernández frente al conflicto, residió en el reconocimiento argentino tanto a nivel bilateral como multilateral del Estado palestino.

La causalidad que explica este ajuste evidencia el peso que durante este periodo cobraron los condicionantes externos entre los que se destacan el accionar de la ANP, que montó una campaña diplomática con vistas a obtener el reconocimiento tanto en el ámbito bilateral como multilateral del Estado palestino. A su vez las gestiones de los estados que componen el mundo árabe, con los cuales Argentina intentaba fortalecer sus vínculos políticos y, todavía más, aquellos comerciales, amén de la vigencia de un contexto internacional propicio para que el país avanzase en tal sentido. Particularmente atendiendo a la buena acogida que recibió la citada campaña de la ANP que derivó en: el reconocimiento bilateral del Estado palestino por parte de diversos actores, entre ellos los países sudamericanos, y el ingreso de Palestina a la UNESCO, sólo por citar algunos resultados de la misma. Esto sin mencionar las transformaciones del sistema internacional crecientemente multipolar, en el marco del cual las decisiones de Argentina ya no se ven constreñidas por el accionar de una única potencia.

Ahora bien, conforme con el trabajo de campo efectuado y la información relevada, se insiste en que este ajuste de la política exterior argentina frente a la disputa tomó lugar en un marco general de continuidad de la política de equidistancia, atendiendo a que Argentina siguió siendo constante en sus reclamos contra: el excesivo uso de la fuerza por parte de Israel, la expansión de los asentamientos judíos, la construcción del muro de separación. Amén de mostrarse firme a la hora de repudiar no sólo el lanzamiento de cohetes sino

67 MISIÓN PERMANENTE DE ARGENTINA ANTE NACIONES UNIDAS, "Intervención de la Embajadora María Cristina Percival, 30 de noviembre de 2012: http://enaun.mrecic.gov.ar/content/tema-37 [Consultado el 12 de junio de 2016]. 
también los actos terroristas perpetuados por grupos armados palestinos; manifestándose, asimismo, a favor del respeto del derecho internacional, de los derechos humanos de ambos pueblos y de la solución pacífica de la controversia sobre la base de la conformación de dos estados. Esto sin mencionar que Argentina reconoció a Palestina sobre la base de las fronteras existentes en 1967 y conforme a lo que las partes determinen en el proceso de negociación, a través de una nota donde se hace expreso el derecho del pueblo palestino a constituir un estado independiente, a la par que se defiende el derecho del Estado de Israel a vivir en paz, dentro de fronteras seguras e internacionalmente reconocidas.

En virtud de lo expuesto, puede concluirse diciendo que, durante las administraciones de Cristina Fernández, Argentina protagonizó un acercamiento a la contraparte palestina dando lugar a un ajuste de su política exterior frente al conflicto palestino-israelí, que tomó lugar en un marco general de continuidad de la política de equidistancia ante la controversia. De esta forma, si bien es cierto que durante el periodo de referencia no existió un cambio de la política frente a la disputa que implicase un quiebre efectivo del patrón de equidistancia, el ajuste sí se hizo presente.

\section{Bibliografía}

AGENCIA JUDÍA DE NOTICIAS, "Cristina Fernández en la Cumbre de MERCOSUR: Hacemos llamado al cese del fuego entre Israel y gaza", 29 Julio de 2014: http://www.agenciajudiadenoticias.com/ shop/detallenot.asp?notid=38821 [Consultado el 2 de septiembre 2014].

AGENCIA JUDÍA DE NOTICIAS, "Flotilla: Fuerte apoyo de la comunidad judía argentina a Israel tras el incidente en Gaza", 30 de junio de 2008: http://www.prensajudia.com/shop/detallenot. asp?notid=20062 [Consultado el 20 de marzo de 2014].

AKMIR, Abdeluahed, Los árabes en Argentina, Editora UNR, Rosario, 2011.

ALONSO, María, ELISALDE, Roberto, VAZQUEZ, Carlos, Historia Argentina y el Mundo Contemporáneo, Aique Grupo Editor, Buenos Aires, 1994.

BOTTA, Paulo, "La diplomacia Argentina y la partición de Palestina desde el punto de vista de sus protagonistas", África del Norte y Medio Oriente, Córdoba, vol. I, nº I, 2010, pp. 5-27.

BOZZOTTI, Agustín y DI JULIO, Inés, "Informe para viaje de negocios", Fundación Exportar, Ministerio de Relaciones Internacionales, Comercio Exterior y Culto, 2016.

CARRANCIO, Magdalena, "Las repercusiones del conflicto de Medio Oriente en la política exterior argentina", en La política exterior argentina: 1994-1997, Ed. CERIR, Rosario, 1998, pp. 149173

CARRANCIO, Magdalena, "La política exterior Argentina y Medio Oriente", en La Política Exterior del Gobierno de Menem. Seguimiento y reflexiones al promediar su mandato, Ed. CERIR, Rosario, 1994, pp. 279-309.

DALMAZZO, Gustavo y FRANCISCO, Héctor, "Los credos de los turcos", Todo es Historia, n 412, 2001.

FABANI, Ornela, "Política exterior argentina frente al conflicto palestino- israelí. Condicionantes internos y externos que contribuyen al predominio del tradicional patrón de equidistancia frente al caso (1983-2011)", trabajo presentado para la obtención del Doctorado en Relaciones Internacionales, Facultad de Ciencia Política y Relaciones Internacionales de la Universidad Nacional de Rosario (UNR), 2015.

FABANI, Ornela, "Las organizaciones comunitarias locales y el proceso de formulación de la política exterior argentina ante la disputa palestino israelí a través de las voces de sus representantes", Revista de Iniciação Científica em Relações Internacionais, Universidades Federal do Paraíba, Vol. 2, No 4, 2015, pp. 56-79. 
HERMANN, Charles, "When governments choose to redirect foreign policy", International Studies Quarterly, Tucson, vol. 34, n¹, 1990, pp. 3-21.

INFOBAE, "Cristina Kirchner será condecorada por su apoyo a Estado al reconocimiento de Palestina como Estado", 8 de agosto de 2015: http://www.infobae.com/2015/08/08/1747071-cristinakirchner-sera-condecorada-su-apoyo-al-reconocimiento-palestina-como-estado/ [Consultado el 5 de abril 2016].

INGRAM, Helen y FIEDERLEIN, Suzzane, "Traversing boundaries: a public policy approach to the analysis of foreign policy", The Western Political Quarterly, vol. 41, n²4, 1988, pp. 725-745

JORQUERA, Miguel, "Es el momento de reconocer a Palestina como Estado", 7 de diciembre de 2010, p. 12.

$\mathrm{KLICH}$, Ignacio, "Argentina, the Middle East and the jews", Universidad de Westminster, Westminster, 1997.

LA GACETA, "Acto de apoyo a Israel en la sede de la AMIA", 9 de enero de 2009.

LA NACIÓN, "Dura respuesta de Argentina a Israel por el caso AMIA", 30 de enero de 2013.

LA NACIÓN, "Contrapuntos entre árabes y judíos por la decisión oficial", 7 de diciembre de 2010.

LA NACIÓN, "Israel califica de lamentable el reconocimiento de Palestina", 6 de diciembre de 2010.

LA NACIÓN, "Polémico reclamo por Malvinas en Qatar", 1 de abril de 2009 LEILLEN, Samuel, "Primer Semestre 2014", Porisrael, 2014: http://porisrael.org/2014/08/06/ israel-comercio-mundial/ [Consultado el 3 de julio 2016].

MÉNDEZ, Norberto, "El rol de las colectividades árabe/islámica y judía respecto del Medio Oriente (19472007). Peso, influencia y presiones de las colectividades en relación con la política interior y exterior del Estado argentino y sobre la sociedad civil argentina global en lo concerniente al conflicto de Medio Oriente y las relaciones interestatales entre la Argentina y países de esta área. La existencia o no de un lobby judío", Tesis Doctoral, Facultad de Ciencias Jurídicas y Sociales, Universidad Nacional de la Plata, 2008.

MIRANDA, Roberto, "El análisis de la política exterior argentina desde la perspectiva de las relaciones internacionales", Cuadernos de Política Exterior Argentina, Centro de Estudios en Relaciones Internacionales de Rosario, Ed. CERIR, Rosario, 1988.

MIRANDA, Roberto, "El cambio externo y las estrategias internacionales de la Argentina", Relaciones Internacionales, Universidad Nacional de la Plata, La Plata, no 21, 2001.

MOYA MENA, Sergio, "Relaciones con Medio Oriente: ¿nuevo eje de la política internacional latinoamericana?", en Revista Relaciones Internacionales, Escuela de Relaciones Internacionales, Universidad de Costa Rica, vol. I, n. 80, 2011, [Consultado el 10 de marzo de 2016].

PAREDES, Rubén, Las relaciones Argentina-Medio Oriente. Un recorrido a lo largo de 1983-2011, Ponenecia presentada en el XI Ccngreso Nacional y IV Congreso Internacional sobre Democracia, Universidad Nacional de Rosario, 8 al 11 de septiembre de 2014.

PERFIL, "Argentina apoyó la investigación de la ONU al ataque israelí", 3 de junio de 2010.

PERINA, Rubén, "El estado de la política exterior y las relaciones internacionales", en PERINA, Rubén y RUSSELL, Roberto (Comp.), Argentina en el mundo (1973-1987), GEL, Buenos Aires,1988.

PUIG, Juan Carlos (Comp.), América Latina: Políticas Exteriores Comparadas, GEL, Buenos Aires, 1984. RED DE MEDIOS ALTERNATIVOS, "Marcha en repudio a la matanza en la Franja de Gaza", 9 de enero de 2009: http://www.rnma.org.ar/nv/index.php?option=com_content\&task=view\&id=510\&Ite $\operatorname{dim}=$ [Consultado el 25 de mayo 2016].

REIN, Raanan, Argentina, Israel y los judíos, Ediciones Lumiere, Buenos Aires, 2007.

RESUMEN LATINOAMERICANO, "Contundente movilización e Buenos Aires contra los bombardeos israelíes sobre Gaza", 17 de julio de 2014: http://www.resumenlatinoamericano.org/2014/07/17/ contundente-movilizacion-en-buenos-aires-contra-los-bombardeos-israelies-sobre-gaza/ [Consultado el 14 de julio 2014].

RUSSELL, Roberto, "Variables Internas y Política Exterior", Ponencia presentada en el Taller de Trabajo sobre Cuestiones Técnicas y Metodológicas para el Estudio de la Política Exterior, FLACSO, Buenos Aires, 18 y 19 de Abril de 1991. 
RUSSELL, Roberto, TOKATLIAN, Juan G., "América Latina y su gran estrategia: entre la aquiescencia y la autonomía", Revista CIDOB d 'Afers Internacionals, n¹04, 2013, pp. 157-180.

SIMONOFF, Alejandro, "Apuntes sobre las políticas exteriores argentinas. Los giros copernicanos y sus tendencias profundas", Instituto de Relaciones Internacionales, Universidad de La Plata, Serie Libros, no 3, 1999.

TELAM, "Yahuar: estamos en un cambio de épocas, con nuevos socios políticos y comerciales", 25 de noviembre de 2012: http://www.telam.com.ar/nota/45060/ [Consultado el 12 de febrero de 2016].

TN, "Argentina reconoce a palestina como Estado Libre e independiente", http://tn.com.ar/politica/ argentina-reconoce-a-palestina-como-un-estado-libre-e-independiente_046773 [Consultado el 10 de febrero 2017].

VAGNI, Juan, "Argentina-Marruecos. De los impulsos a la convergencia político comercial (1989-2007)", Tesis Doctoral, Facultad de Ciencia Política y Relaciones Internacionales, Universidad Nacional de Rosario, 2008.

VAN KLAVEREN, Alberto, "Entendiendo las políticas exteriores latinoamericanas: Modelo para armar", Estudios Internacionales, Santiago de Chile, vol. 25, no 98, 1992, pp. 169-219.

\section{Documentos o comunicados oficiales}

FERNÁNDEZ, Cristina, Discurso ante el Congreso Nacional del Radicalismo Popular, 16 de abril de 2015. FERNÁNDEZ, Cristina, Discurso ante la 66 Asamblea General de Naciones Unidas, 22 de septiembre 2011.

FERNÁNDEZ, Cristina, Discurso ante la 64 Asamblea General de Naciones Unidas, 23 de septiembre de 2009.

FUNDACIÓN EXPORTAR, "Análisis de oportunidades comerciales para el incremento de las exportaciones argentinas hacia Israel", Ministerio de Relaciones Internacionales, Comercio Exterior y Culto, Informe n 34, 2008.

MINISTERIO DE RELACIONES EXTERIORES Y CULTO DE LA REPÚBLICA ARGENTINA, Información para la Prensa no 191/2014, 20 de julio de 2014.

MINISTERIO DE RELACIONES EXTERIORES Y CULTO DE LA REPÚBLICA ARGENTINA, Información para la Prensa no 009/2009, 15 de enero de 2009.

MINISTERIO DE RELACIONES EXTERIORES Y CULTO DE LA REPÚBLICA ARGENTINA, Información para la Prensa no 002/2009, 3 de enero de 2009.

MINISTERIO DE RELACIONES EXTERIORES Y CULTO DE LA REPÚBLICA ARGENTINA, Información para la Prensa, no 559/10, 6 de diciembre de 2010.

MISIÓN PERMANENTE DE ARGENTINA ANTE NACIONES UNIDAS, "Intervención de la Embajadora María Cristina Percival, 30 de noviembre de 2012: http://enaun.mrecic.gov.ar/content/tema-37 [Consultado el 12 de junio de 2016).

MISIÓN PERMANENTE DE ARGETINA ANTE NACIONES UNIDAS, "La presidente pidió a la ONU que llame a Israel y a Palestina al cese inmediato de hostilidades", 19 de noviembre de 2012 http:// enaun.mrecic.gov.ar/content/la-presidenta-pidio-la-onu-que-llame-israel-y-palestina-al-ceseinmediato-de-hostilidades [Consultado el 5 junio de 2016].

MISIÓN PERMANENTE DE ARGETINA ANTE NACIONES UNIDAS, "La situación en el Oriente Medio incluida la cuestión Palestina", 29 de octubre 29 de 2012. 


\section{RELACIONES INTERNACIONALES}

Revista académica cuatrimestral de publicación electrónica Grupo de Estudios de Relaciones Internacionales (GERI) Universidad Autónoma de Madrid, España

www.relacionesinternacionales.info

ISSN 1699 - 3950

ff facebook.com/RelacionesInternacionales

twitter.com/RRInternacional 